\title{
BMJ Open Prevalence of potentially serious alcohol-medication interactions in older adults in a community pharmacy setting: a cross-sectional study
}

\author{
Alice E Holton, ${ }^{1}$ Cora Keeney, ${ }^{1,2}$ Benedict Ryan, ${ }^{1}$ Gráinne Cousins ${ }^{1}{ }^{1}$
}

To cite: Holton AE, Keeney C, Ryan B, et al. Prevalence of potentially serious alcoholmedication interactions in older adults in a community pharmacy setting: a crosssectional study. BMJ Open 2020;10:e035212. doi:10.1136/ bmjopen-2019-035212

- Prepublication history for this paper is available online. To view these files, please visit the journal online (http://dx.doi. org/10.1136/bmjopen-2019035212).

AEH and CK are joint first authors.

Received 24 October 2019 Revised 05 March 2020 Accepted 01 June 2020

Check for updates

(C) Author(s) (or their employer(s)) 2020. Re-use permitted under CC BY-NC. No commercial re-use. See rights and permissions. Published by BMJ.

${ }^{1}$ School of Pharmacy and Biomolecular Sciences, Royal College of Surgeons in Ireland, Dublin 2, Ireland

${ }^{2}$ British Columbia Centre for Excellence in HIV/AIDS, Vancouver, British Columbia, Canada

Correspondence to Dr Gráinne Cousins; gcousins@rcsi.ie

\section{ABSTRACT}

Objective Previous prevalence estimates of POtentially Serious Alcohol-Medication INteractions in Older adults (POSAMINO) are based on in-home inventories of medications; however, this method is associated with under-reporting of medications when compared with dispensing records. This study aims to estimate the prevalence of POSAMINO among community-dwelling older adults using drug dispensing data from the community pharmacy setting.

Design Cross-sectional study.

Setting Irish Community Pharmacy.

Participants 1599 consecutive older adults presenting with a prescription to 1 of 120 community pharmacies nationwide; community-dwelling, aged $\geq 65$ years, able to speak and understand English, with no evidence of cognitive impairment. The mean age of sample was 75.5 years (SD 6.5); $55 \%(n=884)$ female.

Measures 38 POSAMINO criteria were identified using participants' pharmacy dispensing records linked to selfreported alcohol consumption (beverage-specific quantity and frequency measures) over the last 12 months. Results The overall prevalence of POSAMINO in the study population was $28 \%$, with $10 \%$ at risk of at least one POSAMINO criteria and $18 \%$ at risk of two or more. Exposure to POSAMINO most commonly involved cardiovascular agents $(19 \%)$ and central nervous system agents (15\%). Exposure to a higher number of POSAMINO criteria was associated with younger age (adjusted incident rate ratio (AIRR): $0.97 ; 95 \% \mathrm{Cl}: 0.95$ to 0.98 ), male sex (AIRR: 0.55 ; $95 \% \mathrm{Cl}: 0.45$ to 0.67 ) and a higher number of comorbidities (AIRR: 1.05 ; $95 \% \mathrm{Cl}: 1.01$ to 1.13 ).

Conclusion This study adds to the growing body of evidence, which suggests that older adults are vulnerable to potentially serious alcohol-medication interactions, particularly those involving cardiovascular and central nervous system agents, increasing their risk of orthostatic hypotension, gastrointestinal bleeds and increased sedation. Application of the POSAMINO criteria at the point of prescribing may facilitate the risk stratification of older adults and prioritise alcohol screening and brief alcohol interventions in those at greatest risk of harm.

\section{INTRODUCTION}

Alcohol is estimated to be the seventh leading risk factor for the global burden of mortality
Strengths and limitations of this study

- This study examined the prevalence of potentially serious alcohol-medication interactions in community-dwelling older adults using POtentially Serious Alcohol-Medication INteractions in Older adults (POSAMINO) criteria, which avoids overestimating risk by excluding interactions which are of limited clinical significance.

- Objective evaluation of medication exposures, using pharmacy dispensing records, reduces the risk of bias in recall and reporting of medications.

- Although alcohol consumption involved self-report measures, the use of beverage-specific quantity and frequency alcohol measures, with flash cards, reduce the risk of under-reporting alcohol consumption.

- We cannot exclude potential selection bias, as we excluded participants who did not routinely attend the same pharmacy during the observation period.

and disability-adjusted life-years, with older adults experiencing a heightened susceptibility for alcohol-related harm. ${ }^{12}$ Even at relatively low levels of alcohol consumption, older adults are vulnerable to alcohol-related harms due to age-related physiological and anatomical changes. ${ }^{3}$ While alcohol consumption changes over the life course, with a reduction in consumption with age, evidence from UK and Irish prospective cohort studies has shown that the number of drinking occasions tend to become more frequent among older adults. ${ }^{45}$ The use of multiple medications also increases with age, making older adults particularly susceptible to harm arising from alcohol-medication interactions, such as increased sedation, hypoglycaemia, enhanced orthostatic hypotension, increased risk of gastrointestinal bleeds and liver damage. ${ }^{67} \mathrm{~A}$ recent systematic review estimated that between one-in-five and onein-three older adults are potentially susceptible to alcohol-medication interactions. ${ }^{8}$ 
However, these estimates may be biased as there was a lack of consensus regarding what constitutes an alcohol interactive medication across studies, and many of the proposed interactions were theoretical with trivial clinical significance. Furthermore, most studies failed to acknowledge that certain interactions may occur with any alcohol, whereas others may follow a dose response, with severity and risk of the interaction increasing with increasing levels of alcohol consumption. ${ }^{78}$

To address these limitations, we developed the POtentially Serious Alcohol-Medication INteractions in Older adults (POSAMINO) criteria, an explicit set of 38 potentially serious alcohol-medication interactions in older adults, using a two-step process involving a systematic review and a two-round Delphi process. ${ }^{8} 9$ The POSAMINO criteria are organised according to British National Formulary (BNF) physiological classification: central nervous system (CNS) $(\mathrm{n}=15)$, cardiovascular system $(n=9)$, endocrine system $(n=5)$, musculoskeletal system $(n=3)$, infections $(n=3)$, malignant disease and immunosuppression $(n=2)$ and respiratory system $(n=1)$. In our initial validation of the POSAMINO criteria using the first three waves of The Irish Longitudinal Study of Ageing (TILDA), we estimated that $18 \%$ of older adults are at risk of any potentially serious alcohol-medication interactions, with $8 \%$ at risk of one potentially serious alcohol-medication interaction and $10 \%$ at risk of two or more. ${ }^{10}$ These estimates were observed using an in-home inventory of regular medications, which when compared with pharmacy dispensing records is associated with an under-reporting of psychotropics, analgesics, antiinflammatories and antirheumatics. ${ }^{112}$ Consequently, our previous estimates of POSAMINO exposure may represent an underestimate, particularly for CNS agents, which have been shown to be associated with adverse outcomes. We found that exposure to CNS POSAMINO criteria was associated with a $19 \%$ increase in risk for falling and an $8 \%$ increase in injurious falls at 4-year follow-up among older community-dwelling adults. ${ }^{13}$ Therefore, the aim of this study was to estimate the prevalence of POSAMINO among community-dwelling older adults using drug dispensing data from the community pharmacy setting.

\section{METHODS}

\section{Study setting and design}

We conducted a cross-sectional study, recruiting participants from 120 community pharmacies across the Republic of Ireland between May and August 2017. Community pharmacies were selected on the basis of participation in the National Pharmacy Internship Programme. Consecutive participants were invited to take part if they met the following inclusion criteria: presenting to a participating pharmacy to fill their own prescription (for any prescribed medication), aged 65 years or older, community dwelling, able to speak and understand English, and no evidence of cognitive impairment. After obtaining informed consent, participants completed a structured face-to-face interview conducted by trained pharmacy interns. Each interview was subsequently linked to participants' dispensing records from that pharmacy for the 12 months preceding interview. The Strengthening the Reporting of Observational Studies in Epidemiology (STROBE) standardised reporting guidelines for cross-sectional studies have been adhered to for the reporting of this research. ${ }^{14}$

\section{Patient and public involvement}

Patients were not involved in the design, conduct or reporting of this study.

\section{Application of the POSAMINO criteria}

Potentially serious alcohol-medication interactions according to the POSAMINO criteria were identified using participants' pharmacy dispensing records and selfreported alcohol consumption over the last 12 months. Medications were coded using the WHO Anatomical Therapeutic Chemical (ATC) classification system. Participants, who reported drinking alcohol in the past 12 months, completed beverage-specific quantity and frequency measures for beer/cider, wine and spirits, as recommended by international guidelines for alcohol measurement in general population surveys. ${ }^{15}$ Quantity was measured by asking participants to think of a typical day in the last 12 months on which they drank wine, for example, and how many standards drinks of wine they drank. In Ireland, a standard drink contains $10 \mathrm{~g}$ of pure alcohol and is equivalent to half a pint of beer or cider, a single pub measure of spirits, a small $(100 \mathrm{~mL})$ glass of wine or bottle of alcopops. Participants were provided with beverage-specific flash cards so that they could accurately report how many standard drinks they consumed for each drink type. The trained interviewer facilitated the conversion of number of drinks to standard drinks for each beverage. Average weekly alcohol consumption was calculated as total grams of alcohol consumed per week. As the POSAMINO criteria specify 'any alcohol consumption' or 'heavy alcohol consumption' depending on the medication, we categorised participants as current drinkers (drank alcohol in the past 12 months) or heavy drinkers if they reported drinking in excess of $60 \mathrm{~g}$ alcohol per drinking occasion or $>110 \mathrm{~g}$ alcohol/week for women or $>170 \mathrm{~g}$ alcohol/week for men.

\section{Statistical analysis}

Statistical analyses were performed using STATA V.15.0. The overall prevalence of POSAMINO and the prevalence per individual POSAMINO criterion were calculated as a proportion of all eligible participants. The prevalence of each criterion was also calculated as a proportion of current drinkers and those participants taking the medicine of interest. Logistic regression and negative binomial regression models were used to identify factors associated with experiencing any POSAMINO and the number of POSAMINO, respectively. Models were adjusted for age, gender, area of residence, education status, polypharmacy, self-rated health, smoking status and number of 


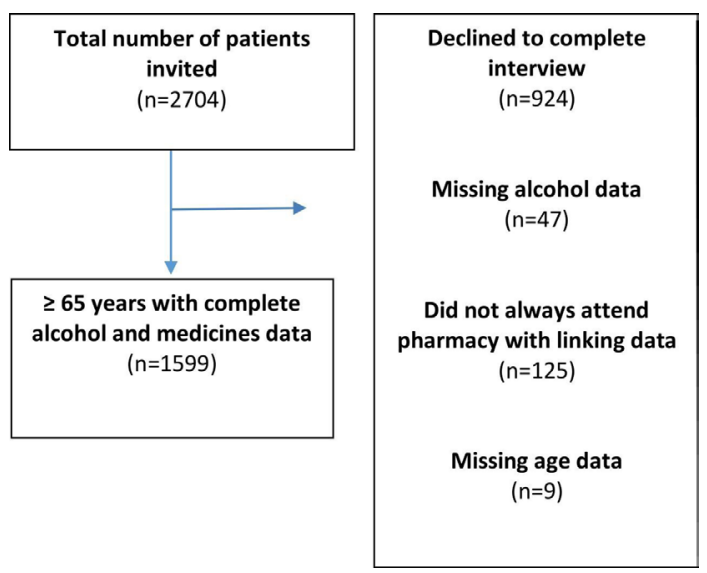

Figure 1 Flow diagram of study participants.

comorbidities. Polypharmacy was defined as the use of five or more medications. ${ }^{16-18}$ Medicines dispensed during the observation period were also used to identify medical conditions using the validated Rx-Risk tool. ${ }^{19} \mathrm{We}$ mapped the Rx-Risk tool to the International Classification of Diseases, Tenth Revision (ICD-10), by matching the disease categories to ICD-10 chapter groupings. ${ }^{20}$

\section{RESULTS}

\section{Description of study population}

In total, 2704 consecutive patients were invited to participate, $1780(65.8 \%)$ consented to complete the interview and have it linked to their pharmacy dispensing records. Subsequently, we excluded participants attending other pharmacies as their pharmacy records were incomplete $(\mathrm{n}=125)$, and those with incomplete alcohol data $(\mathrm{n}=47)$ and missing data on age $(n=9)$, leaving a final sample of 1599 participants. Figure 1 outlines the flow of participants through the study.

The mean age of this sample was 75.5 years (SD 6.5) and $55 \%$ were female $(\mathrm{n}=884)$. Two-thirds $(67 \%$; $\mathrm{n}=1065$ ) of participants were identified as current drinkers, with $27 \%$ identified as heavy drinkers. Men were significantly more likely to be heavy drinkers, relative to women ( $40 \%$ vs $17 \%, \mathrm{p}<0.001)$. Alcohol consumption declined with age, $72 \%$ of adults aged 65-69 years were identified as current drinkers compared with $61 \%$ of adults aged $\geq 80$ years. Polypharmacy was identified in $70 \%$ of the sample. Using the Rx-Risk tool, participants were found to have an average of six conditions (SD 2.9). The most common comorbidities included diseases of the circulatory system $(90 \%)$, the digestive system (57\%) and mental and behavioural disorders $(35 \%)$. Further characteristics of the study sample are presented in table 1.

\section{Prevalence of potentially serious alcohol-medication} interactions

The overall prevalence of POSAMINO among the total sample was $28 \%$, with $10 \%$ of participants at risk of one potentially serious alcohol-medication interaction and $18 \%$ at risk of two or more serious interactions. Among current drinkers, $42 \%$ were at risk of any POSAMINO, with $15 \%$ at risk of one POSAMINO and $27 \%$ at risk of 2 or more. Table 2 shows the prevalence of the POSAMINO criteria according to physiological system. An estimated $19 \%$ of participants were identified as being at risk of a serious alcohol-medication interaction due to their concurrent use of alcohol with cardiovascular agents. Heavy alcohol consumption with low-dose Aspirin was the most common potentially serious interaction, with an estimated 13\% of participants at risk. This was followed by heavy alcohol consumption with multiple antihypertensive combinations (12\%). An estimated $15 \%$ of participants were identified as at risk due to their concurrent use of alcohol with CNS agents, particularly in relation to concurrent alcohol use with long-term paracetamol $(7.3 \%)$, benzodiazepines and benzodiazepine-related medications $(5.5 \%)$ and opioids $(4.6 \%)$. Further analysis found that of those meeting the criteria for benzodiazepines and benzodiazepine-related medications, $90 \%$ $(\mathrm{n}=79)$ had a prescription for 84 days or over. In addition, approximately one-in-four older adults who were dispensed benzodiazepines reported concurrent heavy drinking. A similar estimate was observed among those dispensed opioids (25.6\%), with almost two-thirds of participants dispensed tricyclic antidepressants reporting concurrent alcohol use.

The regression analyses (table 3 ) showed that older age (adjusted OR (AOR): 0.95 ; $95 \%$ CI: 0.93 to 0.97 ) and female gender (AOR: 0.42; 95\% CI: 0.33 to 0.53 ) were associated with lower odds of any POSAMINO, while urban dwellers (AOR: 1.40; 95\% CI: 1.05 to 1.86) and higher number of comorbidities (AOR: 1.09; 95\% CI: 1.03 to 1.14 ) were associated with a higher odds of any POSAMINO exposure. A similar pattern was observed from the negative binomial regression analysis, which also showed that older age (adjusted incident rate ratio (AIRR): $0.97 ; 95 \%$ CI: 0.95 to 0.98 ) and female gender (AIRR: 0.55 ; $95 \%$ CI: 0.45 to 0.67 ) were associated with a lower number of POSAMINO criteria. While, a higher number of comorbidities (AIRR: 1.05; 95\% CI: 1.01 to 1.13 ) were associated with a greater number of POSAMINO criteria.

\section{DISCUSSION}

In this cohort of 1599 community-dwelling older adults, we observed that more than one-in-four were at risk of a potentially serious alcohol-medication interaction according to the POSAMINO criteria, with almost onein-five at risk of two or more potentially serious interactions. Risk of exposure to multiple POSAMINO criteria was associated with younger age, male sex and a higher number of comorbidities. This is the first study to investigate the prevalence of potentially serious alcohol-medication interactions in community-dwelling older adults using drug dispensing records from the participants' community pharmacy. When we compare our estimates from this study with our previous study of older adults 
Table 1 Characteristics of sample by POSAMINO exposure

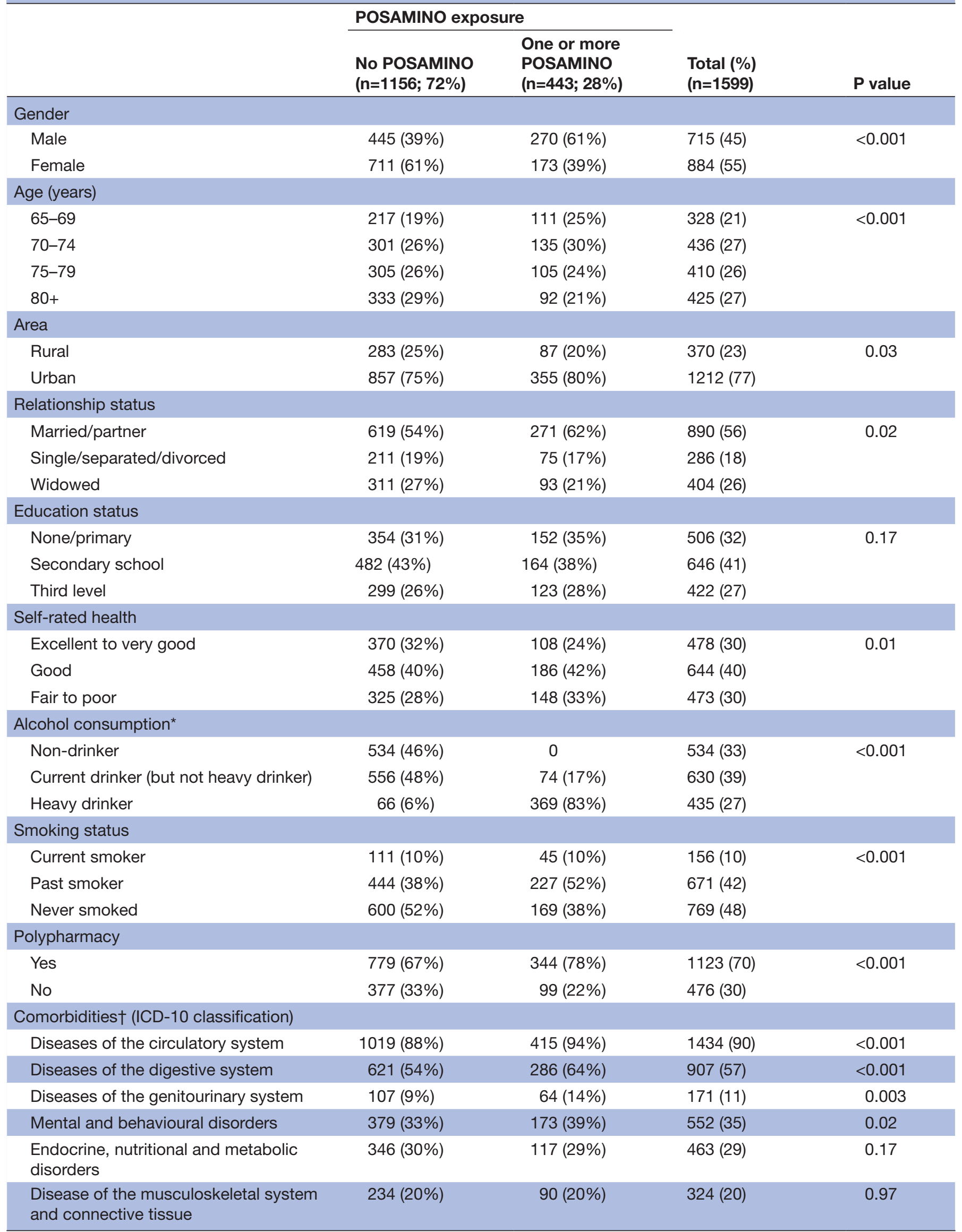




\begin{tabular}{|c|c|c|c|c|}
\hline & \multicolumn{2}{|c|}{ POSAMINO exposure } & \multirow[b]{2}{*}{$\begin{array}{l}\text { Total }(\%) \\
(\mathrm{n}=1599)\end{array}$} & \multirow[b]{2}{*}{$P$ value } \\
\hline & $\begin{array}{l}\text { No POSAMINO } \\
(n=1156 ; 72 \%)\end{array}$ & $\begin{array}{l}\text { One or more } \\
\text { POSAMINO } \\
(n=443 ; 28 \%)\end{array}$ & & \\
\hline Diseases of the nervous system & $130(11 \%)$ & $71(16 \%)$ & $201(13)$ & 0.01 \\
\hline Diseases of the respiratory system & $324(28 \%)$ & $121(27 \%)$ & $445(28)$ & 0.02 \\
\hline
\end{tabular}

*Alcohol consumption was based on self-reported alcohol consumption in the past 12 months: non-drinkers reported not drinking in the past 12 months; current drinkers (drank alcohol in the past 12 months); heavy drinkers (reported drinking $>60 \mathrm{~g}$ alcohol per drinking occasion or drinking >110 $\mathrm{g}$ alcohol/week for women or >170 $\mathrm{g}$ alcohol/week for men).

†Determined by the Rx-Risk tool.

ICD-10, International Classification of Diseases, Tenth Revision; POSAMINO, POtentially Serious Alcohol-Medication INteractions in Older adults.

in TILDA, using an in-home inventory for ascertainment of medications, we note a higher risk of exposure to any potentially serious alcohol-medication interactions using POSAMINO (28\% vs $18 \%$ in TILDA) and to number of POSAMINO criteria ( $18 \%$ with $\geq 2$ POSAMINO criteria vs $8 \%$ in TILDA). ${ }^{10}$ Both studies suggest that older adults are at greatest risk of potentially serious alcohol-medication interactions due to their concurrent use of alcohol with cardiovascular agents, with almost $19 \%$ of the current sample exposed to POSAMINO criteria involving cardiovascular agents compared with $15 \%$ in TILDA. The second most common criteria involve CNS agents. However, in TILDA we estimated exposure to POSAMINO criteria involving CNS agents at $4 \%$ compared with our current estimate of $15 \%$. This difference is not accounted for by exposure to alcohol consumption, as estimates of current drinkers (67\% vs $64 \%$ in TILDA) and heavy drinking $(27 \%$ vs $27 \%$ in TILDA) were comparable across cohorts. The observed difference may arise from the different methods of ascertaining exposure to medications, in-home inventory compared with pharmacy dispensing records, particularly in relation to CNS agents. As previously noted, self-reports or in-home inventories of medications such as analgesics and psychotropics are lower when compared with dispensing records. ${ }^{11} 12$ It has been suggested that medications stored by the bedside maybe forgotten during in-home inventory, and stigmatisation bias potentially affects self-reporting of psychotropic medications. ${ }^{11}$

While the estimates observed here are higher than our previous validation of POSAMINO criteria, they are lower than a number of previous studies examining the concurrent use of alcohol with medications, which estimated that between $31 \%$ and $39 \%$ of older adults are at risk of drug-alcohol interactions. ${ }^{21-25}$ The POSAMINO criteria represent potentially serious alcohol-medication interactions, with specific alcohol consumption patterns specified for each individual criteria. ${ }^{10}$ In contrast, considerable heterogeneity was observed in the inclusion of medications in previous studies and estimates related to the concurrent use of any alcohol consumption, ${ }^{21-25}$ which may overestimate the potential risk when interactions are likely to occur with concurrent heavy alcohol consumption. ${ }^{8}$

The strengths of this study include the recruitment of community-dwelling older adults from a national sample of pharmacies in Ireland, using a consecutive recruitment process. Although consecutive recruitment involves nonprobabilistic sampling, it provides structured recruitment ensuring all participants can be enrolled, thus producing a more representative sample of the target population than convenience sampling. ${ }^{26}{ }^{27}$ Furthermore, the use of POSAMINO criteria, which focus on potentially serious alcohol-medication interactions, avoids overestimating risk by excluding those interactions, which are of limited clinical significance. In addition, medication use was evaluated objectively using pharmacy dispensing records. However, dispensing of medications from the pharmacy does not necessarily guarantee adherence. ${ }^{28}$ A further limitation was the use of self-report measures for alcohol consumption, which may have introduced potential biases in recall and reporting. This may have led to the misclassification of participants, especially for POSAMINO criteria involving heavy alcohol consumption, as older adults are more likely to under-report heavy consumption. ${ }^{29-31}$ However, the use of beverage-specific quantity and frequency measures, using flash cards, may have facilitated more accurate responses. ${ }^{15}$ In addition, levels of alcohol consumption observed in this study are similar to those reported in previous population studies of older adults. ${ }^{32} 33$ Future studies of POSAMINO could further reduce the potential risk of under-reporting of alcohol consumption by asking participants to pour a simulated drink, particularly for beverages, which often involve free pouring such as wine and spirits. ${ }^{3435}$ A study of 844 current drinkers aged 65-74 years in Australia found that older men poured drinks that were $32 \%$ larger than a standard drink of $10 \mathrm{~g}$ alcohol, with older women pouring drinks that were $16 \%$ larger. $^{36}$ Furthermore, in the absence of internationally agreed age-specific drinking guidelines, we used national Irish recommendations to define heavy alcohol consumption in the development of the POSAMINO criteria ${ }^{9}$ and in this study to classify participants as heavy drinkers. Given that older 
Table 2 Number and prevalence of POSAMINO criteria among total sample, current drinkers and those using medications included in POSAMINO

\begin{tabular}{|c|c|c|c|c|}
\hline Criteria description & $\begin{array}{l}\text { Number of people } \\
\text { fitting POSAMINO } \\
\text { criteria }\end{array}$ & $\begin{array}{l}\% \text { of total sample } \\
(n=1599)\end{array}$ & $\begin{array}{l}\% \text { of current } \\
\text { drinkers } \\
(n=1065)\end{array}$ & $\begin{array}{l}\% \text { taking } \\
\text { medication class* }\end{array}$ \\
\hline Cardiovascular system & 297 & 19 & 27.9 & 27.9 \\
\hline $\begin{array}{l}\text { Heavy alcohol consumption with multiple } \\
\text { antihypertensive combinations }\end{array}$ & 188 & 12 & 17.7 & 28.0 \\
\hline $\begin{array}{l}\text { Heavy alcohol consumption with warfarin } \\
\text { (and phenindione) }\end{array}$ & 27 & 2 & 2.5 & 26.7 \\
\hline $\begin{array}{l}\text { Heavy alcohol consumption with regular } \\
\text { use of low dose aspirin }(75 \mathrm{mg})\end{array}$ & 204 & 13 & 19.2 & 30.4 \\
\hline $\begin{array}{l}\text { Heavy alcohol consumption with both } \\
\text { regular and as required nitrates (eg, } \\
\text { glyceryl trinitrate, isosorbide dinitrate and } \\
\text { isosorbide mononitrate) }\end{array}$ & 21 & 1 & 2.0 & 31.3 \\
\hline $\begin{array}{l}\text { Heavy alcohol consumption with the } \\
\text { vasodilatory medication nicorandil }\end{array}$ & 0 & 0 & 0 & 0 \\
\hline $\begin{array}{l}\text { Heavy alcohol consumption with the } \\
\text { combined use of both nitrates and } \\
\text { vasodilator medication (eg, nicorandil) }\end{array}$ & 0 & 0 & 0 & 0 \\
\hline $\begin{array}{l}\text { Heavy alcohol consumption with diuretics } \\
\text { (eg, loop diuretics (furosemide), thiazide } \\
\text { diuretics (bendroflumethiazide) and } \\
\text { potassium sparing diuretics (amiloride)) }\end{array}$ & 77 & 4.8 & 7.2 & 25.2 \\
\hline $\begin{array}{l}\text { Heavy alcohol consumption with alpha } \\
\text { blockers (eg, terazosin) }\end{array}$ & 20 & 1.3 & 1.9 & 27.0 \\
\hline $\begin{array}{l}\text { Heavy alcohol consumption with centrally } \\
\text { acting antihypertensives (eg, clonidine or } \\
\text { methyldopa) }\end{array}$ & 0 & 0 & 0 & 0 \\
\hline Respiratory system & 10 & 0.6 & 0.9 & 52.6 \\
\hline $\begin{array}{l}\text { Any alcohol consumption with } \\
\text { first generation antihistamines (eg, } \\
\text { promethazine) }\end{array}$ & 10 & 0.6 & 0.9 & 52.6 \\
\hline Central nervous system & 241 & 15 & 22.6 & 30.4 \\
\hline $\begin{array}{l}\text { Heavy alcohol consumption with } \\
\text { benzodiazepines (eg, diazepam) and } \\
\text { benzodiazepine-related medications (eg, } \\
\text { zopiclone) }\end{array}$ & 88 & 5.5 & 8.3 & 24.3 \\
\hline $\begin{array}{l}\text { Heavy alcohol consumption combined } \\
\text { with opioids }\end{array}$ & 73 & 4.6 & 6.9 & 25.6 \\
\hline $\begin{array}{l}\text { Heavy alcohol consumption with all } \\
\text { antipsychotics }\end{array}$ & 7 & 0.4 & 0.7 & 14.6 \\
\hline $\begin{array}{l}\text { Heavy alcohol consumption with } \\
\text { antiepileptic drugs }\end{array}$ & 35 & 2.2 & 3.3 & 23.6 \\
\hline $\begin{array}{l}\text { Any alcohol consumption with tricyclic } \\
\text { antidepressants }\end{array}$ & 45 & 2.8 & 4.2 & 66.7 \\
\hline $\begin{array}{l}\text { Any alcohol consumption with } \\
\text { mirtazapine }\end{array}$ & 19 & 1.2 & 1.8 & 55.9 \\
\hline $\begin{array}{l}\text { Any alcohol consumption with } \\
\text { monoamine oxidase inhibitors }\end{array}$ & 0 & 0 & 0 & 0 \\
\hline $\begin{array}{l}\text { Heavy alcohol consumption with long- } \\
\text { term regular paracetamol use (eg, } 1 \mathrm{~g} \text { four } \\
\text { times a day) }\end{array}$ & 118 & 7.3 & 11.1 & 23.7 \\
\hline
\end{tabular}


Table 2 Continued

\begin{tabular}{|c|c|c|c|c|}
\hline Criteria description & $\begin{array}{l}\text { Number of people } \\
\text { fitting POSAMINO } \\
\text { criteria }\end{array}$ & $\begin{array}{l}\% \text { of total sample } \\
(n=1599)\end{array}$ & $\begin{array}{l}\% \text { of current } \\
\text { drinkers } \\
(n=1065)\end{array}$ & $\begin{array}{l}\% \text { taking } \\
\text { medication class }\end{array}$ \\
\hline $\begin{array}{l}\text { Heavy alcohol consumption with } \\
\text { apomorphine }\end{array}$ & 0 & 0 & 0 & 0 \\
\hline Endocrine system & 60 & 3.8 & 5.6 & 24.8 \\
\hline Heavy alcohol consumption with insulin & 15 & 0.9 & 1.4 & 25.4 \\
\hline $\begin{array}{l}\text { Heavy alcohol consumption with } \\
\text { metformin }\end{array}$ & 53 & 3.3 & 5.0 & 26.8 \\
\hline $\begin{array}{l}\text { Heavy alcohol consumption with } \\
\text { sulphonylureas }\end{array}$ & 14 & 0.9 & 1.31 & 17.3 \\
\hline $\begin{array}{l}\text { Heavy alcohol consumption with } \\
\text { thiazolidinediones (eg, pioglitazone) }\end{array}$ & 0 & 0 & 0 & 0 \\
\hline Musculoskeletal and joint diseases & 71 & 4.4 & 6.7 & 30.6 \\
\hline $\begin{array}{l}\text { Heavy alcohol consumption with any } \\
\text { non-steroidal anti-inflammatory drugs } \\
\text { (including COX- } 2 \text { inhibitors) }\end{array}$ & 63 & 3.9 & 5.9 & 29.9 \\
\hline $\begin{array}{l}\text { Heavy alcohol consumption combined } \\
\text { with methotrexate or leflunomide }\end{array}$ & 7 & 0.4 & 0.7 & 25.0 \\
\hline Malignant disease and immunosuppression & 0 & 0 & 0 & 0 \\
\hline $\begin{array}{l}\text { Any alcohol consumption with } \\
\text { procarbazine }\end{array}$ & 0 & 0 & 0 & 0 \\
\hline Any alcohol consumption with cycloserine & 0 & 0 & 0 & 0 \\
\hline $\begin{array}{l}\text { Any alcohol consumption with } \\
\text { metronidazole or tinidazole }\end{array}$ & 49 & 3.1 & 4.6 & 75.4 \\
\hline
\end{tabular}

Any individual POSAMINO criteria with less than five individuals are not reported in this table to ensure anonymity of respondents.

${ }^{*} T$ The denominator for medication users varied across drug classes; cardiovascular system $(n=1066)$; respiratory system ( $\left.n=19\right)$; central nervous system $(n=791)$; endocrine system $(n=241)$; musculoskeletal and joint diseases $(n=231)$; malignant disease and immunosuppression $(n=0)$; infection $(n=65)$.

POSAMINO, POtentially Serious Alcohol-Medication INteractions in Older adults.

adults are more vulnerable to harm even at low levels of alcohol consumption, our estimates of POSAMINO may reflect an underestimate of the true prevalence among older adults particularly for those criteria involving heavy alcohol consumption. Finally, we cannot exclude selection bias as we excluded participants who reported attending other pharmacies.

This study adds to the growing body of evidence, which suggests that older adults are vulnerable to potentially serious alcohol-medication interactions, particularly those involving cardiovascular and CNS agents, increasing their risk of orthostatic hypotension, gastrointestinal bleeds and increased sedation. Furthermore, the absolute number at risk of potentially serious alcohol-medication interactions involving CNS agents is likely to be higher than previously estimated. ${ }^{10}$ The POSAMINO criteria may be useful in a clinical setting to risk-stratify patients at the point of prescribing, particularly among younger older adults, men and those with multiple comorbidities, allowing for the identification of patients whose alcohol 
Table 3 Logistic regression and negative binomial regression models for any and number of POSAMINO among total sample $(n=1599)$

\begin{tabular}{|c|c|c|}
\hline & $\begin{array}{l}\text { Adjusted OR } \\
(95 \% \mathrm{Cl})\end{array}$ & $\begin{array}{l}\text { Adjusted IRR } \\
(95 \% \mathrm{Cl})\end{array}$ \\
\hline & Any POSAMINO* & Number of POSAMINO† \\
\hline Women (vs men) & $0.42(0.33$ to 0.53$) \ddagger$ & $0.55(0.45$ to 0.67$) \ddagger$ \\
\hline Urban (vs rural) & 1.40 (1.05 to 1.86$) \ddagger$ & 1.25 (0.99 to 1.58$)$ \\
\hline Third level (vs none/primary) & 1.07 (0.78 to 1.43$)$ & $1.03(0.81$ to 1.31$)$ \\
\hline Polypharmacy & $1.28(0.92$ to 1.79$)$ & $1.21(0.91$ to 1.59$)$ \\
\hline \multicolumn{3}{|l|}{ Self-reported health status } \\
\hline Good (vs excellent) & $1.27(0.94$ to 1.70$)$ & $1.18(0.92$ to 1.50$)$ \\
\hline Never smoker (vs current smoker) & $1.02(0.67$ to 1.54$)$ & $1.00(0.71$ to 1.41$)$ \\
\hline Number of comorbidities (using Rx-Risk Comorbidity Index) & 1.09 (1.03 to 1.14$) \ddagger$ & $1.05(1.01$ to 1.13$) \ddagger$ \\
\hline
\end{tabular}

*Logistic regression model of any POSAMINO; OR and 95\% Cl.

†Negative binomial regression model of number of POSAMINO criteria; IRR and $95 \% \mathrm{Cl}$.

$\ddagger$ Statistical significance $\mathrm{P}<0.05$.

IRR, incident rate ratio; POSAMINO, POtentially Serious Alcohol-Medication INteractions in Older adults.

consumption places them at increased risk of harm. POSAMINO criteria could also be integrated into pharmacy dispensing systems, as part of a Screening, Brief Intervention and Referral to Treatment (SBIRIT) intervention. Discussing the risk of alcohol more broadly and alcohol-medication interactions more specifically at the point of prescribing or dispensing may reduce the risk of harm arising from the concurrent use of alcohol and medications, since many patients may simply be unaware of the potential risk, ${ }^{37}$ and once informed may reduce their alcohol consumption. A recent systematic review found that older adults considered themselves as responsible drinkers, often not recognising the risks associated with their alcohol consumption. ${ }^{38}$ Others may benefit from a brief intervention or referral to specialist services. Finally, the association between POSAMINO criteria and adverse outcomes in terms of morbidity and mortality requires further investigation to inform the development of targeted interventions aimed at reducing alcoholrelated harm in older adults.

In conclusion, our study confirms previous findings, which indicate that there is a high propensity for alcohol-medication interactions among older adults, particularly in relation to cardiovascular and CNS agents. Application of the POSAMINO criteria at the point of prescribing or dispensing medications may facilitate the risk stratification of older adults and prioritise alcohol screening and brief alcohol interventions in those at greatest risk of harm.
Acknowledgements The authors would like to acknowledge the Pharmaceutical Society of Ireland (PSI), for whom the Royal College of Surgeons in Ireland (RCSI) manages the National Pharmacy Internship Programme (NPIP). They also thank all pharmacists who contributed to and facilitated the undertaking of this study.

Contributors GC, AEH, CK and BR were involved in the conception and design of the study, interpreted the data, drafted the manuscript, revised the manuscript and gave final approval of the version to be published and agreed to be accountable for all aspects of the work, ensuring that questions related to the accuracy or integrity of any part of the work are appropriately investigated and resolved. AEH, CK and GC undertook the acquisition and analysis of the work.

Funding This project was supported by the Royal College of Surgeons in Ireland. Competing interests None declared.

Patient consent for publication Not required.

Ethics approval Ethical approval was obtained from the Royal College of Surgeons in Ireland, with all participants providing written informed consent (REC1365).

Provenance and peer review Not commissioned; externally peer reviewed.

Data availability statement No data are available.

Open access This is an open access article distributed in accordance with the Creative Commons Attribution Non Commercial (CC BY-NC 4.0) license, which permits others to distribute, remix, adapt, build upon this work non-commercially, and license their derivative works on different terms, provided the original work is properly cited, appropriate credit is given, any changes made indicated, and the use is non-commercial. See: http://creativecommons.org/licenses/by-nc/4.0/.

ORCID iD

Gráinne Cousins http://orcid.org/0000-0003-2985-7668

\section{REFERENCES}

1 Knott CS, Scholes S, Shelton NJ. Could more than three million older people in England be at risk of alcohol-related harm? A cross- 
sectional analysis of proposed age-specific drinking limits. Age Ageing 2013;42:598-603.

2 GBD 2016 Risk Factors Collaborators. Global, regional, and national comparative risk assessment of 84 behavioural, environmental and occupational, and metabolic risks or clusters of risks, 1990-2016: a systematic analysis for the global burden of disease study 2016. Lancet 2017;390:1345-422.

3 Meier P, Seitz HK. Age, alcohol metabolism and liver disease. Curr Opin Clin Nutr Metab Care 2008;11:21-6.

4 Britton A, Ben-Shlomo Y, Benzeval M, et al. Life course trajectories of alcohol consumption in the United Kingdom using longitudinal data from nine cohort studies. BMC Med 2015;13:47.

5 Holton A, Boland F, Gallagher P, et al. Life course transitions and changes in alcohol consumption among older lrish adults: results from the Irish longitudinal study on ageing (TILDA). J Aging Health 2019;31:1568-88.

6 Weathermon R, Crabb DW. Alcohol and medication interactions. Alcohol Res Health 1999;23:40-54.

7 Moore AA, Whiteman EJ, Ward KT. Risks of combined alcohol/ medication use in older adults. Am J Geriatr Pharmacother 2007;5:64-74.

8 Holton AE, Gallagher P, Fahey T, et al. Concurrent use of alcohol interactive medications and alcohol in older adults: a systematic review of prevalence and associated adverse outcomes. BMC Geriatr 2017; $17: 148$

9 Holton $\mathrm{AE}$, Gallagher PJ, Ryan C, et al. Consensus validation of the POSAMINO (potentially serious Alcohol-Medication interactions in older adults) criteria. BMJ Open 2017;7:e017453.

10 Holton A, Boland F, Gallagher P, et al. Longitudinal prevalence of potentially serious alcohol-medication interactions in communitydwelling older adults: a prospective cohort study. Eur J Clin Pharmacol 2019;75:569-75.

11 Richardson K, Kenny RA, Peklar J, et al. Agreement between patient interview data on prescription medication use and pharmacy records in those aged older than 50 years varied by therapeutic group and reporting of indicated health conditions. J Clin Epidemiol 2013;66:1308-16.

12 Nielsen MW, Søndergaard B, Kjøller M, et al. Agreement between self-reported data on medicine use and prescription records vary according to method of analysis and therapeutic group. $J$ Clin Epidemiol 2008;61:919-24.

13 Holton A, Boland F, Gallagher P, et al. Potentially serious alcoholmedication interactions and falls in community-dwelling older adults: a prospective cohort study. Age Ageing 2019;48:824-31.

14 von Elm E, Altman DG, Egger M, et al. The strengthening the reporting of observational studies in epidemiology (STROBE) statement: guidelines for reporting observational studies. J Clin Epidemiol 2008:61:344-9.

15 Nugawela MD, Langley T, Szatkowski L, et al. Measuring alcohol consumption in population surveys: a review of international guidelines and comparison with surveys in England. Alcohol Alcohol 2016;51:84-92.

16 Hovstadius B, Hovstadius K, Astrand B, et al. Increasing polypharmacy - an individual-based study of the Swedish population 2005-2008. BMC Clin Pharmacol 2010;10:16.

17 Richardson K, Kenny RA, Bennett K. The effect of free health care on polypharmacy: a comparison of propensity score methods and multivariable regression to account for confounding. Pharmacoepidemiol Drug Saf 2014;23:656-65.

18 Gnjidic D, Hilmer SN, Blyth FM, et al. Polypharmacy cutoff and outcomes: five or more medicines were used to identify communitydwelling older men at risk of different adverse outcomes. J Clin Epidemiol 2012;65:989-95.
19 Pratt NL, Kerr M, Barratt JD, et al. The validity of the Rx-Risk comorbidity index using medicines mapped to the anatomical therapeutic chemical (ATC) classification system. BMJ Open 2018;8:e021122.

20 Lalic S, llomäki J, Bell JS, et al. Prevalence and incidence of prescription opioid analgesic use in Australia. Br J Clin Pharmacol 2019;85:202-15.

21 Adams WL. Potential for adverse drug-alcohol interactions among retirement community residents. J Am Geriatr Soc 1995;43:1021-5.

22 Aira M, Hartikainen S, Sulkava R. Community prevalence of alcohol use and concomitant use of medication--a source of possible risk in the elderly aged 75 and older? Int J Geriatr Psychiatry 2005;20:680-5.

23 Breslow RA, Dong C, White A. Prevalence of alcohol-interactive prescription medication use among current drinkers: United States, 1999 to 2010. Alcohol Clin Exp Res 2015;39:371-9.

24 Swift W, Stollznow N, Pirotta M. The use of alcohol and medicines among Australian adults. Aust N Z J Public Health 2007;31:529-32.

25 Wong $\mathrm{H}$, Heuberger R, Logomarsino J, et al. Associations between alcohol use, polypharmacy and falls in older adults. Nurs Older People 2016;28:30-6.

26 Dillon P, Smith SM, Gallagher PJ, et al. Association between gaps in antihypertensive medication adherence and injurious falls in older community-dwelling adults: a prospective cohort study. BMJ Open 2019;9:e022927.

27 Dillon P, Smith SM, Gallagher P, et al. Impact of financial burden, resulting from prescription co-payments, on antihypertensive medication adherence in an older publically insured population. BMC Public Health 2018;18:1282.

28 Sattler ELP, Lee JS, Perri M. Medication (re)fill adherence measures derived from pharmacy claims data in older Americans: a review of the literature. Drugs Aging 2013;30:383-99.

29 Kuerbis A, Sacco P, Blazer DG, et al. Substance abuse among older adults. Clin Geriatr Med 2014;30:629-54.

30 Merrick EL, Horgan CM, Hodgkin D, et al. Unhealthy drinking patterns in older adults: prevalence and associated characteristics. $J$ Am Geriatr Soc 2008;56:214-23.

31 Hajat S, Haines A, Bulpitt C, et al. Patterns and determinants of alcohol consumption in people aged 75 years and older: results from the MRC trial of assessment and management of older people in the community. Age Ageing 2004;33:170-7.

32 Breslow RA, Castle I-JP, Chen CM, et al. Trends in alcohol consumption among older Americans: National health interview surveys, 1997 to 2014. Alcohol Clin Exp Res 2017;41:976-86.

33 Molander RC, Yonker JA, Krahn DD. Age-Related changes in drinking patterns from mid- to older age: results from the Wisconsin longitudinal study. Alcohol Clin Exp Res 2010;34:no-92.

34 Bright SJ, Williams CM. Development of Australia's first older adultspecific early intervention for alcohol-related harm: feasibility and proof of concept. Australas J Ageing 2017;36:52-5.

35 Bright SJ, Williams CM. Evaluation of Australia's first older adultspecific early intervention for reducing alcohol-related harm. Aust. Health Review 2018;42:676-9.

36 Wilkinson C, Allsop S, Chikritzhs T. Alcohol pouring practices among 65- to 74-year-olds in Western Australia. Drug Alcohol Rev 2011;30:200-6

37 Zanjani F, Hoogland Al, Downer BG. Alcohol and prescription drug safety in older adults. Drug Healthc Patient Saf 2013;5:13-27.

38 Bareham BK, Kaner E, Spencer LP, et al. Drinking in later life: a systematic review and thematic synthesis of qualitative studies exploring older people's perceptions and experiences. Age Ageing 2019;48:134-46. 